\title{
POSITIVE SOLUTIONS TO ITERATIVE SYSTEMS OF \\ FRACTIONAL ORDER THREE-POINT BOUNDARY VALUE \\ PROBLEMS WITH RIEMANN-LIOUVILLE DERIVATIVE
}

\author{
K. R. PRASAD AND B. M. B. KRUShnA
}

\begin{abstract}
In this paper, we determine the eigenvalues $\lambda_{i}, 1 \leqslant i \leqslant n$, for which there exist positive solutions for the iterative system of fractional order three-point boundary value problems by applying fixed point theorem.
\end{abstract}

Mathematics subject classification (2010): 26A33, 34B15, 34B18. lution.

Keywords and phrases: Fractional derivative, boundary value problem, Green's function, positive so-

\section{REFERENCES}

[1] Z. BAI AND H. Lü, Positive solutions for boundary value problems of nonlinear fractional differential equations, J. Math. Anal. Appl., 311 (2005), 495-505.

[2] M. Benchohra, J. Henderson, S. K. Ntoyuas And A. Ouahab, Existence results for fractional order functional differential equations with infinite delay, J. Math. Anal. Appl., 338 (2008), $1340-1350$.

[3] K. Diethelm And N. Ford, Analysis of fractional differential equations, J. Math. Anal. Appl., 265 (2002), 229-248.

[4] L. H. ERBE AND H. WANG, On the existence of positive solutions of ordinary differential equations, Proc. Amer. Math. Soc., 120 (1994), 743-748.

[5] C. Goodrich, Existence of a positive solution to a class of fractional differential equations, Comput. Math. Appl., 59 (2010), 3489-3499.

[6] D. Guo And V. Lakshmikantham, Nonlinear Problems in Abstract Cones, Academic Press, Orlando, 1988.

[7] J. Henderson AND S. K. NTOUYAs, Positive solutions for systems of nonlinear boundary value problems, Nonlinear Stud., 15 (2008), 51-60.

[8] J. M. DAVIS, J. HENDERSON, K. R. PRASAD AND W. YIN, Eigenvalue intervals for non-linear right focal problems, Appl. Anal., 74 (2000), 215-231.

[9] E. R. Kauffman And E. Mboumi, Positive solutions of a boundary value problem for a nonlinear fractional differential equation, Elec. J. Qual. Theory Diff. Equ., 3 (2008), 1-11.

[10] R. A. KhAN, M. RehmAn AND J. Henderson, Existence and uniqueness of solutions for nonlinear fractional differential equations with integral boundary conditions, Fract. Diff. Calc., 1 (2011), 29-43.

[11] A. A. Kilbas, H. M. SRivasthava and J. J. Trujillo, Theory and Applications of Fractional Differential Equations, North-Holland Mathematics Studies, vol. 204, Elsevier science, Amsterdam, 2006.

[12] M. A. Krasnosel'S KiI, Positive Solutions of Operator Equations, Noordhoff, Groningen, 1964.

[13] K. S. Miller And B. Ross, An Introduction to Fractional Calculus and Fractional Differential Equations, John Wiley and Sons, New York, 1993.

[14] I. Podulbny, Fractional Differential Equations, Academic Press, San Diego, 1999.

[15] K. R. Prasad AND B. M. B. KRushna, Multiple positive solutions for a coupled system of Riemann-Liouville fractional order two-point boundary value problems, Nonlinear Stud., 20 (2013), 501-511. 
[16] K. R. PRASAD AND B. M. B. KRushna, Eigenvalues for iterative systems of Sturm-Liouville fractional order two-point boundary value problems, Fract. Calc. Appl. Anal., 17 (2014), 638-653. 